\title{
Identification of Peptide Ligands for Targeting to the Blood-Brain Barrier
}

\author{
Inge van Rooy, ${ }^{1,6}$ Serpil Cakir-Tascioglu, ${ }^{1}$ Pierre-Olivier Couraud, ${ }^{2,3}$ Ignacio A. Romero, ${ }^{4}$ Babette Weksler, ${ }^{5}$ \\ Gert Storm, ${ }^{1}$ Wim E. Hennink, ${ }^{1}$ Raymond M. Schiffelers, ${ }^{1}$ and Enrico Mastrobattista ${ }^{1}$
}

Received October 14, 2009; accepted January 5, 2010; published online February 17, 2010

\begin{abstract}
Purpose. Transport of drugs to the brain is limited by the blood-brain barrier. New, specific brain endothelium ligands can facilitate brain-specific delivery of drugs.

Methods. We used phage display in an in situ brain perfusion model to screen for new brain endothelium peptide ligands.

Results. Two phage clones, displaying 15 amino acid-peptides (GLA and GYR) that were selected for brain binding in the mouse model, showed significant binding to human brain endothelium (hCMEC/ D3), compared to a random control phage. This binding was not seen for other human endothelial cells (HUVEC). Binding to hCMEC/D3 cells was dose dependent. When phage GLA and GYR were individually perfused through the murine brain, their ability to bind to the brain was 6-fold (GLA) and 5fold (GYR) higher than the control phage. When compared to lung perfusion, phage showed an 8.5 -fold (GYR) and 48-fold (GLA) preference for brain over lung compared to the control.

Conclusions. These results indicate that two new peptide ligands have been identified that may be used for specific targeting of drugs to the blood-brain barrier.
\end{abstract}

KEY WORDS: blood-brain barrier; brain targeting; peptide ligand; phage display; targeting ligand.

\section{INTRODUCTION}

Transport of drugs to the brain is limited by the presence of the blood-brain barrier (BBB). This barrier is formed by specialized endothelial cells and supported by other cell types, such as astrocytes and pericytes (1). The BBB regulates homeostasis of the brain and is selectively permeable for the uptake and efflux of ions, nutrients and metabolites (2). Drug transport via the paracellular route is prevented by tight junctions between the endothelial cells. Free diffusion via the transcellular route is accessible only to lipophilic compounds smaller than approximately $400 \mathrm{Da}$ (3). This limits the treatment of many brain diseases, such as Alzheimer's disease and Parkinson's disease. Even in certain pathological situations where the $\mathrm{BBB}$ is partly disrupted, drug transport remains limited (4).

\footnotetext{
${ }^{1}$ Department of Pharmaceutics, Utrecht Institute for Pharmaceutical Sciences (UIPS), Utrecht University, P.O. Box 80082, 3508 TB, Utrecht, The Netherlands.

${ }^{2}$ Institut Cochin, Université Paris Descartes, CNRS (UMR 8104), Paris, France.

${ }^{3}$ Inserm, U567, Paris, France.

${ }^{4}$ Department of Biological Sciences, The Open University, Milton Keynes, UK.

${ }^{5}$ Department of Medicine, Weill Medical College, New York, New York, USA.

${ }^{6}$ To whom correspondence should be addressed. (e-mail: i.vanrooy@ uu.nl)
}

To overcome this limitation, carrier systems, such as nanoparticles, have been used to deliver drugs to the brain. Antibody ligands have been successfully coupled to the nanoparticles to target the brain endothelial cell receptors $(5,6)$. The main receptors that have been targeted are the transferrin receptor (7) and the insulin receptor (8). However, these receptors are not brain specific. They are widely expressed in peripheral organs (9), limiting their selectivity and applicability as brain-targeting receptors. Therefore, identification of new brain targets is needed to deliver drugs more selectively into the brain. The objective of this study was to identify new targeting ligands that can be used for active targeting of drug delivery systems to the brain, aiming for selectivity for brain endothelium.

Peptides are highly suitable for ligand screening, when expressed on a phage display system, and they have been widely used as targeting ligands (10). Phage display is a powerful technology for ligand identification (11-14). Large libraries expressing peptides or proteins can be screened for target affinity (15). We used a random 15-mer peptide library to identify brain-targeting peptide ligands. In vivo, bloodbrain barrier endothelial cells get stimulated by their surrounding cells $(16,17)$ and intraluminal blood flow (18). This contributes to the complexity of the blood-brain barrier and regulates the expression of specific receptors at the cell surface in a polarized fashion. For this reason, ligand screening should preferably be performed in vivo. However, as in vivo phage screening in humans was impossible for ethical reasons, we chose to pre-select phage in a mouse perfusion 
model to enrich for peptides recognizing brain endothelial cells in their natural environment. Because the brain remains intact, the endothelial cells keep their polarity and their contact with the surrounding cells, maintaining expression of relevant receptors. After the pre-selection for in vivo relevant receptors, identified ligands were tested for cross-reactivity with human cell-surface receptors expressed by human endothelial cells in vitro. In this way, the complexity of the in vivo $\mathrm{BBB}$ and the significance of the human $\mathrm{BBB}$ were combined.

\section{MATERIALS AND METHODS}

\section{Phage Library and Bacteria}

Filamentous phage fd-tet, which confers tetracycline resistance on the host (19), was used for this study. Random peptide library f3-15mer (20), containing $2.5 \times 10^{8}$ primary clones (GenBank Accession AF246445) with foreign 15-mer peptide displayed on pIII was provided by George P. Smith (Columbia, MO). Kanamycin resistant E. coli K91BluKan (K91BK) host bacteria were also provided by George P. Smith. The K91BK sex is Hfr Cavalli, resulting in deployment of the $\mathrm{F}$ pilus, the attachment site for filamentous phage infection.

\section{Animals}

In situ phage display screening was performed in male, 6-8 week-old C57Bl/6 mice (Charles River, The Netherlands). Perfusion of single clones was done in male $28-32 \mathrm{~g}$ Balb/c mice (Harlan, Horst, The Netherlands). Food and water were supplied ad libitum. Animal studies were performed according to national regulations and were approved by the local animal experiments ethical committee.

\section{In Situ Brain Perfusion of Phage}

Forty units of heparin (Sigma) were injected i.v. into the tail vein to prevent coagulation of blood inside the microvessels (21). Five minutes after injection, mice were sacrificed by $\mathrm{CO}_{2}$ asphyxiation. Next, thorax was opened, and bulldog clamps with $8 \times 1.2 \mathrm{~mm}$ serrated jaws (WPI, Berlin, Germany) were placed on descending aorta (left from the carotid arteries) and pulmonary veins and arteries. Inferior caval vein was cut to allow outflow of perfused fluids. A $26 \mathrm{G}$ needle, connected to a peristaltic pump, was inserted into the left ventricle of the heart (22). Mice were initially perfused with $1.5 \mathrm{ml}$ Hanks' Balanced Salt Solution (HBSS, $\mathrm{pH}$ 7.0-7.4, Invitrogen, Carlsbad, CA) in all experiments. Directly afterwards, mice were perfused with phage. Upon the three selection rounds, $1 \mathrm{ml}$ of phage library in HBSS $\left(8.9 \times 10^{11} \mathrm{TU}, 3.1 \times 10^{11} \mathrm{TU}\right.$, and $4.8 \times 10^{10}$ TU for the first, second and third selection rounds, respectively) were perfused (input). To wash away non-binders, $3.5 \mathrm{ml}$ HBSS was perfused directly afterwards. For the third selection round, HBSS $+1 \%$ FBS was used instead of HBSS. For perfusions of selected phage (single clones), $750 \mu$ l of phage $\left(\sim 10^{10}\right.$ TU) in HBSS $+1 \%$ FBS was perfused, directly followed by $2 \mathrm{ml}$ of HBSS $+1 \%$ serum to wash. Peristaltic pump speed was $200 \mu \mathrm{l} / \mathrm{min}$. Directly after perfusion, brains were taken out. For the phage display screening, phage were isolated from the brain (see below).

\section{Phage Isolation from Brain}

After phage display selection rounds, brain cerebrum was ground in $600 \mu \mathrm{l} 100 \mathrm{mM}$ triethanolamine (Fluka, Munich, Germany) and centrifuged for $10 \mathrm{~min}$ at $3300 \times \mathrm{g}$. Supernatant was transferred to a new tube, neutralized with

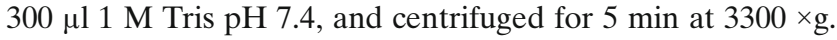
Late $\log$ phase K91BK were obtained by inoculation of $10 \mathrm{ml}$ of terrific broth with $100 \mu \mathrm{l}$ of an overnight culture, and incubation for $4 \mathrm{~h}$ in a shaker incubator $\left(250 \mathrm{rpm}, 37^{\circ} \mathrm{C}\right)$. When late log phase was reached (when the $\mathrm{OD}_{600}$ of a $10 \times$ dilution reached 0.2 on a spectrophotometer), shaking was slowed down to $75 \mathrm{rpm}$ for $5 \mathrm{~min}$ to allow sheared $\mathrm{F}$ pili to regenerate. Brain supernatant was incubated with late log phase K91BK for 10 min to allow phage to infect the bacteria. The infected bacteria were added to $40 \mathrm{ml} \mathrm{LB}$ Broth (Sigma) containing $0.2 \mu \mathrm{g} / \mathrm{ml}$ tetracycline and amplified for $30 \mathrm{~min}$ in a shaker incubator $\left(250 \mathrm{rpm}, 37^{\circ} \mathrm{C}\right)$. Two hundred $\mu \mathrm{l}$ of the infected K91BK were spread on LB agar plates for titration. Tetracycline concentration was then brought to $20 \mu \mathrm{g} / \mathrm{ml}$, and phage were amplified overnight in the shaker incubator. Cultures were cleared of bacteria by two $10 \mathrm{~min}$ centrifugations at 3000 and $8000 \times \mathrm{g}$. To the cleared culture 0.15 volume PEG/NaCl (16.7\% /3.3 M stock) was added (PEG 8000, Promega, Breda, The Netherlands). Phage were precipitated overnight at $4^{\circ} \mathrm{C}$. Precipitated phage were collected by centrifugation for $15 \mathrm{~min}$ at $17500 \times \mathrm{g}$ at $4^{\circ} \mathrm{C}$. Pellets were dissolved in $1 \mathrm{ml}$ TBS and precipitated again with 0.15 vol $\mathrm{PEG} / \mathrm{NaCl}$ for at least $1 \mathrm{~h}$ at $4^{\circ} \mathrm{C}$. Phage were collected by centrifugation for $5 \mathrm{~min}$ at $16000 \times \mathrm{g}$. Pellets were dissolved in $400 \mu \mathrm{l}$ TBS and stored at $4^{\circ} \mathrm{C}$. Two hundred $\mu \mathrm{l}$ of purified phage $+800 \mu \mathrm{l}$ HBSS were used for the next selection round. Three successive selection rounds were done in total. After the third selection round, brain cerebrum was separated into anterior and posterior part. Phage were separately isolated from both parts. Titration of input phage was performed as described below. After perfusion of single phage clones, whole brains were ground in $1,000 \mu \mathrm{l}$ triethanolamine and centrifuged for $10 \mathrm{~min}$ at $3300 \times \mathrm{g}$. Two hundred $\mu \mathrm{l}$ supernatant was transferred to a new tube, and neutralized with $100 \mu 11 \mathrm{M}$ Tris $\mathrm{pH}$ 7.4. Titration of both input and output phage was performed as described below.

\section{Titration of Phage}

Transducing units (TU) were determined by titration. Phage were serially diluted in $0.1 \%(w / v)$ gelatin in TBS. Ten $\mu l$ of phage dilution were incubated with $10 \mu$ of late log phase K91BK for $10 \mathrm{~min}$ at room temperature. One $\mathrm{ml} \mathrm{LB}$, containing $0.2 \mu \mathrm{g} / \mathrm{ml}$ tetracycline, was added. This was incubated for $40 \mathrm{~min}$ in a shaker incubator $\left(250 \mathrm{rpm}, 37^{\circ} \mathrm{C}\right)$. Two-hundred $\mu \mathrm{l}$ of the infected K91BK were spread on LB agar plates containing $40 \mu \mathrm{g} / \mathrm{ml}$ tetracycline and $100 \mu \mathrm{g} / \mathrm{ml}$ kanamycin. Plates were incubated overnight at $37^{\circ} \mathrm{C}$. The next day, the number of colonies was counted, and the number of transducing units was calculated. Input phage were titrated as well at the same time for recovery percentage calculations. 


\section{Immunohistochemistry Brain Cryosections}

Frozen untreated brains were coated with OCT embedding matrix (Cellpath, Newtown, UK). Sections were cut along the sagittal plane using low-profile microtome blades (Leica, Heidelberg, Germany) on a CM3050 cryostat (Leica). Sections were transferred onto Superfrost Plus glass slides (Menzel, Germany). Section thickness was $5 \mu \mathrm{m}$. They were dried overnight at room temp and stored at $-80^{\circ} \mathrm{C}$. Upon use, sections were allowed to thaw for $20 \mathrm{~min}$, fixed in acetone for $10 \mathrm{~min}$, and air dried for $30 \mathrm{~min}$. Separate sections were encircled with a liquid-repellent marker. All incubations were done in a moist environment, and incubation volumes were $90 \mu \mathrm{l} /$ section. Non-specific binding sites and endogenous biotin were blocked simultaneously with avidin/biotin-blocking solution in PBS + 5\% FCS (Vector Laboratories, Inc., Burlingame, USA), according to manufacturer's instructions. Brain sections were incubated with either the enriched library or the unselected library (both $2.37 \times 10^{13} \mathrm{~V} / \mathrm{ml}$ ) for $1 \mathrm{~h}$ at room temperature. Sections were incubated with $0.8 \mu \mathrm{g} / \mathrm{ml}$ biotinylated anti-phage antibody (Abcam, Cambridge, UK) for $1 \mathrm{~h}$. Thereafter, sections were incubated with $5 \mu \mathrm{g} / \mathrm{ml}$ alexa568conjugated streptavidin (Invitrogen) for $35 \mathrm{~min}$. Sections were mounted in FluorSave (Calbiochem, San Diego, CA) and viewed under a Nikon Eclipse TE2000-U epi-fluorescence microscope (Nikon, Tokyo, Japan) at a $20 \times$ magnification.

\section{Sequence Alignment}

Peptide sequences were aligned to check for peptides' consensus sequences along the 15 amino acids. Software used was Vector NTI Advance 10 AlignX (Invitrogen).

\section{Cells}

Human brain endothelial cells (hCMEC/D3) were obtained from Institut National de la Santé et de la Recherche Médicale (INSERM, Paris, France). Cells were cultured at $37^{\circ} \mathrm{C}, 5 \% \mathrm{CO}_{2}$, in EBM-2 basal medium supplemented with EGM-2 MV BulletKit (Lonza, Basel, Switzerland), containing growth factors and $2.5 \%$ FBS. Additionally, $10 \mathrm{mM}$ HEPES, $1 \mathrm{ng} / \mathrm{ml}$ bFGF (Invitrogen), and antibiotics (Penicillin and Streptomycin) were added. hCMEC/D3 cells were grown on surfaces coated with $100 \mu \mathrm{g} /$ $\mathrm{ml}$ Rat tail collagen type 1 (BD Biosciences). Prior to use, cell culture medium was replaced by cell differentiation medium, consisting of EBM-2 basal medium supplemented with $2.5 \%$ FBS, $1.4 \mu \mathrm{M}$ hydrocortisone, $1 \mathrm{ng} / \mathrm{ml} \mathrm{bFGF}, 10 \mathrm{mM}$ HEPES, and antibiotics. Cells were grown to a monolayer in differentiation medium for one week. Medium was replaced every 2-3 days.

Human umbilical vein endothelial cells (HUVEC) were cultured at $37^{\circ} \mathrm{C}, 5 \% \mathrm{CO}_{2}$, in EBM-2 basal medium supplemented with antibiotics and EGM-2 BulletKit (Lonza), containing growth factors and $2 \%$ FBS.

\section{In Vitro Binding of Single Phage Clones}

Cells were seeded at $3.4 \cdot 10^{5}$ cells/well in 12-well plates. Single phage clones were diluted to $\sim 10^{10} \mathrm{TU} / \mathrm{ml}$ in $25 \mathrm{mM}$ HEPES in HBSS, and $1 \mathrm{ml}$ phage solution was incubated with either hCMEC/D3 or HUVEC cells for $1 \mathrm{~h}$ at $37^{\circ} \mathrm{C}$. The buffer containing unbound phage was removed, and cells were washed three times with PBS. Cells were washed three times with $1 \mathrm{ml}$ of $0.2 \mathrm{M}$ glycine ( $\mathrm{pH} 2.2$ ) to elute surfacebound phage $(23,24)$. Three $\mathrm{ml}$ wash eluate was collected and neutralized with $0.45 \mathrm{ml} 1 \mathrm{M}$ tris ( $\mathrm{pH}$ 9.1). Cells were washed again with $1 \mathrm{ml}$ of PBS and were subsequently lysed with $0.25 \mathrm{ml} 100 \mathrm{mM}$ triethanolamine for $10 \mathrm{~min}(25,26)$. Cell lysates were collected and neutralized with $0.0625 \mathrm{ml} 1 \mathrm{M}$ tris (pH 7.4). The neutralized wash eluates (binding fraction) and cell lysates (strong binding/uptake fraction) were titrated as described above. Input phage were titrated as well at the same time for recovery percentage calculations.

\section{Immunohistochemistry hCMEC/D3 Cells}

hCMEC/D3 cells were grown to a monolayer on rat tail collagen coated Lab-Tek chamber slides (Nunc, Rochester, NY). Single phage clones were diluted to $5 \cdot 10^{12} \mathrm{~V} / \mathrm{ml}$ in HBSS, and $100 \mu \mathrm{l}$ phage solution or $100 \mu \mathrm{l}$ HBSS only was incubated with the cells for $1 \mathrm{~h}$ at $37^{\circ} \mathrm{C}$. The buffer containing unbound phage was removed, and cells were washed three times with PBS. Cells were fixed in $4 \%$ formaldehyde for $30 \mathrm{~min}$. Cells were washed two times with PBS and incubated with $0.8 \mu \mathrm{g} / \mathrm{ml}$ biotinylated anti-phage antibody for $1 \mathrm{~h}$. Thereafter, cells were incubated with $5 \mu \mathrm{g} / \mathrm{ml}$ alexa568conjugated streptavidin for $35 \mathrm{~min}$, and washed three times. Cells were incubated with 300 nM DAPI (Invitrogen) for $2 \mathrm{~min}$ and washed three times with demi water. Cells were mounted in FluorSave and viewed under a Nikon Eclipse TE2000-U epi-fluorescence microscope at a $20 \times$ magnification.

\section{In Situ Lung Perfusion of Phage}

In situ lung perfusion was performed in the same way as was done for brain perfusions of single clones, with the only modification being the placement of the bulldog clamps. The ascending aorta was clamped, and phage were perfused through the left ventricle of the heart. Inferior caval vein was cut to allow outflow of perfused fluids. Phage isolation and titration were also performed in the same way as was done for the brain perfusions.

\section{Statistical Analysis}

Data were analyzed using Graphpad Prism 4 for Windows software (Graphpad Software, San Diego, CA).

\section{RESULTS}

In situ phage display screening was used as a tool to search for new blood-brain-barrier-binding peptides. Screening was performed by perfusion of a 15 amino acid random peptide phage display library through the murine brain in situ. Phage perfusion $(27,28)$ was chosen over intravenous injection, because clearance of phage occurs rapidly via the major organs of the reticuloendothelial system (mainly liver and spleen), resulting in a half-life of fd-tet of only $12 \mathrm{~min}$ (29). Therefore, phage were directly perfused via the heart through the brain, preventing loss to other organs, and 
ensuring a high fraction of individual peptide-displaying phage to reach the target tissue.

Various in situ brain perfusion methods have been developed (30). Most models have been established in rats, but murine models have been used as well $(22,31,32)$. Most perfusion models have been used to study brain uptake of substrates and were performed under anesthesia. Since filamentous phage are approximately $1 \mu \mathrm{m}$ in size (33), they are not likely to be taken up into the brain, and the perfusion allows screening for binding rather than for internalizing peptides. Therefore, body temperature maintenance was not required, and perfusion was performed at room temperature, postmortem. The large majority of brain proteins are stable during a postmortem interval of up to $4 \mathrm{~h}$ at $25^{\circ} \mathrm{C}$ (34). As perfusions were completed within $30 \mathrm{~min}$ after sacrifice, the postmortem state was not expected to cause significant changes in brain microvessel morphology.

Phage were infused via the heart. The major advantage compared to direct infusion into the brain is that the phage have to travel some distance before they reach the brain. On their way, they already encounter endothelial cells: the endothelium of the aorta and carotid arteries. Phage with affinity to ubiquitous endothelial receptors are given the opportunity to bind to these cells and will not reach the brain. This negative selection filters out unspecific binders and allows for the identification of peptides that bind more specifically to brain endothelium $(35,36)$.

Phage display screening was performed by perfusion of a mouse brain with $8.9 \times 10^{11}$ Transducing Units (TU) in Hanks' Balanced Salt Solution (HBSS), containing $1 \mathrm{~g} / \mathrm{L}$ glucose, to keep the brain in a viable state. Phage were perfused for $5 \mathrm{~min}$. Phage incubation times of 5-15 $\mathrm{min}$ are common and have been successful in vivo (11,37-40). Non-binders were washed away by perfusion of HBSS. The brain was taken out, and phage were isolated from the cerebrum and submitted to the next selection round. During the third selection round, $1 \%$ FBS was added to the HBSS to limit unspecific interactions. Because the infused fluid was not evenly perfused throughout the brain (see supporting information paragraph), cerebrum was divided into its anterior (weakly perfused) and posterior (strongly perfused) side after the third selection round to investigate whether different ligands could be identified in the different brain parts.

After three successive selection rounds, 17 clones isolated from the anterior part and 17 clones isolated from the posterior part of the brain were sequenced (Table I). Two of the sequences were found twice, once in the anterior part and once in the posterior part. However, most of the sequences were found only once. There was no clear discrimination in amino acid sequence between clones isolated from the different brain parts. Alignment analysis revealed no consensus sequences. This is not surprising, considering the complexity of the brain endothelium surface and the many possible targets it may contain.

After selection, the enriched library was tested for its ability to bind to the brain by immunohistochemistry. Frozen untreated murine brains were sectioned, and both the unselected (naive) and enriched library were incubated on the brain sections. Bound phage were stained with a labeled anti-phage antibody. Fluorescence microscopy revealed that the enriched library showed enhanced bind- ing to the brain sections, compared to the naive library (Fig. 1). The staining was comparable in the anterior and posterior side.

The peptides were selected for affinity to the in vivo relevant murine brain. However, for clinical applications, affinity for human endothelium is desired. Cross-reactivity between mouse and human has been shown for phage display selected peptides (39). Therefore, a number of selected and sequenced phage clones were tested for their ability to bind human brain endothelial cells (picked at random from Table IA, B). Additionally, three clones were randomly chosen from the naive library as a negative control (Table IC). The hCMEC/D3 cell line was used to represent the human blood-brain barrier. hCMEC/D3 is a stable, fully characterized, well-differentiated human brain endothelial cell line $(41,42)$. Phage were added to the cells and incubated for $1 \mathrm{~h}$ at $37^{\circ} \mathrm{C}(23,25,43)$. Cell-associated phage were recovered in two steps $(25,26)$ - first, by washing the cell surface with a low $\mathrm{pH}$ glycine buffer (stripping surfacebound phage) and subsequently by lysing the cells (collecting strongly bound and internalized phage). The percentages of recovered phage (percentage from input) are shown in Fig. 2. Fig. 2A shows that only seven out of nineteen selected clones showed higher binding to the cells compared to the highest random control clone (SVE). This may be due to non-specific electrostatic interactions of the peptides with the cell membranes, limiting discrimination between specific and non-specific binders. However, when looking at strong binding/internalization, these non-specific interactions are at background level. As shown in Fig. 2B, seventeen out of nineteen selected clones showed a higher cell association as compared to the highest random control clone (YLR), indicating that peptides were identified that can specifically associate with brain endothelial cells. When the anterior and posterior sides of the cerebrum are compared, phage isolated from the posterior side showed significantly higher cell association (Fig. 2B) than phage isolated from the anterior side. This can be correlated to the perfusion pattern seen upon Evans blue perfusion, which showed better perfusion through the posterior side of the brain (see supporting information paragraph). Likely, more individual phage reached the posterior side, increasing the selection strength and resulting in stronger binding phage. Of all clones tested in vitro, phage GLA and GYR showed the best brain endothelium binding. Therefore, GLA and GYR were chosen for further testing.

In order to investigate dose dependency, binding of phage GLA, GYR, and negative control YLR to the hCMEC/D3 cells was determined for different concentrations of input phage. Fig. 3 shows that the phage bound to the cells in a dose-dependent manner. Significantly more GLA and GYR were bound to the cells compared to control phage YLR.

The results indicate that phage GLA and GYR show affinity for the hCMEC/D3 brain endothelium. We tested in vitro whether this affinity was brain-specific or whether these phage have affinity for other endothelial cells as well. Therefore, phage association was tested on non-brain endothelium: human umbilical vein endothelial cells (HUVEC). Best hCMEC/D3 binding phage GLA and GYR were tested, as well as poor hCMEC/D3 binding 
Table I. Sequenced Phage Clones. Clones After 3 Selection Rounds, Isolated from Anterior (A) and Posterior (B) Cerebrum. Control Clones (C), Randomly Taken from Naive Library. Isoelectric Point (pI) and Charge at pH 7 Were Calculated by Vector NTI Advance 10 AlignX Software. Clones Tested In Vitro $(y=$ yes) are Shown in Fig. 2

\begin{tabular}{|c|c|c|c|c|c|c|}
\hline Clone & Name & Sequence & Frequency & $\mathrm{pI}$ & charge at $\mathrm{pH} 7$ & Tested in vitro \\
\hline \multicolumn{7}{|c|}{ A. Clones isolated from anterior cerebrum } \\
\hline A1 & RFL & RFLEFPRFFPAIILP & 1 & 9.60 & +0.76 & \\
\hline $\mathrm{A} 2$ & PGR & PGRLLPGVIQRHFFI & 1 & 12.50 & +1.85 & \\
\hline A3 & GAF & GAFSSPRSLTVPLRR & 1 & 12.80 & +2.76 & \\
\hline A4 & PFA & PFARAPVEHHDVVGL & 2 & 5.99 & -1.06 & $\mathrm{y}$ \\
\hline A5 & CGG & CGGLFAGCAALIDVF & 1 & 3.80 & -1.26 & $\mathrm{y}$ \\
\hline A6 & EFP & EFPTFSWSYINDSLL & 1 & 3.67 & -2.24 & \\
\hline A7 & ADW & ADWPHARGKFALGNA & 1 & 8.75 & +0.85 & $\mathrm{y}$ \\
\hline A8 & GFT & GFTDVHLHLPGNSHR & 1 & 7.02 & +0.02 & $\mathrm{y}$ \\
\hline A9 & GLD & GLDLLGDVRIPVVRR & 2 & 9.51 & +0.76 & $\mathrm{y}$ \\
\hline A10 & PVA & PVAGMPLFPTAWFAH & 1 & 6.74 & -0.15 & \\
\hline A11 & SAY & SAYAATVRGPLSSAS & 1 & 8.75 & +0.76 & $\mathrm{y}$ \\
\hline A12 & RYA & RYASQLSDQILFTLP & 1 & 5.84 & -0.24 & $\mathrm{y}$ \\
\hline A13 & RDG & RDGAFSPPVRWWSFS & 1 & 9.60 & +0.76 & \\
\hline A14 & TGA & TGAQAGLHEWRPWGV & 1 & 6.75 & -0.15 & \\
\hline A15 & EDW & EDWFSASIRRVPTFA & 1 & 6.07 & -0.24 & $\mathrm{y}$ \\
\hline A16 & GTW & GTWSSTCPLCSATAV & 1 & 5.51 & -0.26 & $\mathrm{y}$ \\
\hline A17 & PWL & PWLPSNLGSRPGLMR & 1 & 12.50 & +1.76 & \\
\hline \multicolumn{7}{|c|}{ B. Clones isolated from posterior cerebrum } \\
\hline $\mathrm{P} 1$ & GVV & GVVNYARAFNVGAAV & 1 & 8.75 & +0.76 & $\mathrm{y}$ \\
\hline $\mathrm{P} 2$ & GLD & GLDLLGDVRIPVVRR & 2 & 9.51 & +0.76 & $\mathrm{y}$ \\
\hline P3 & HAA & HAAFEPRGDVRHTLL & 1 & 6.92 & -0.06 & $\mathrm{y}$ \\
\hline P4 & GDG & GDGRFHFLRGFFDSD & 1 & 5.30 & -1.15 & $\mathrm{y}$ \\
\hline P5 & VRS & VRSIALFPPEWSATS & 1 & 6.00 & -0.24 & $\mathrm{y}$ \\
\hline P6 & GLA & GLAHSFSDFARDFVA & 1 & 5.21 & -1.15 & $\mathrm{y}$ \\
\hline P7 & VTG & VTGTQIRLPAYLRFD & 1 & 8.75 & +0.76 & \\
\hline P8 & GYR & GYRPVHNIRGHWAPG & 1 & 10.84 & +1.93 & $\mathrm{y}$ \\
\hline P9 & ITR & ITRGGYVIYHDALLA & 1 & 6.74 & -0.15 & \\
\hline $\mathrm{P} 10$ & GAY & GAYFLSNHAVVRGVG & 1 & 8.75 & +0.85 & \\
\hline P11 & PFA & PFARAPVEHHDVVGL & 2 & 5.99 & -1.06 & $\mathrm{y}$ \\
\hline $\mathrm{P} 12$ & VGR & VGRPGGLVGGFASSL & 1 & 9.75 & +0.76 & \\
\hline $\mathrm{P} 13$ & LGR & LGRAGQSYPSFARGL & 1 & 10.83 & +1.76 & $\mathrm{y}$ \\
\hline $\mathrm{P} 14$ & VVS & VVSSRSVLSSQYRGH & 1 & 10.84 & +1.85 & $\mathrm{y}$ \\
\hline $\mathrm{P} 15$ & ALP & ALPCNGAGCSRVTAR & 1 & 9.02 & +1.74 & $\mathrm{y}$ \\
\hline P16 & VPM & VPMGLGFLGRGLAPL & 1 & 9.75 & +0.76 & \\
\hline P17 & RSS & RSSHHPSFAVSLEPL & 1 & 6.92 & -0.06 & $\mathrm{y}$ \\
\hline \multicolumn{7}{|c|}{ C. Random control clones } \\
\hline $\mathrm{C} 1$ & SVE & SVEVALVPGRQSRHF & - & 9.61 & +0.85 & $\mathrm{y}$ \\
\hline $\mathrm{C} 2$ & YLR & YLRWAALCSIGSSCW & - & 8.06 & +0.74 & $\mathrm{y}$ \\
\hline $\mathrm{C} 3$ & RVR & RVREPYPGMLERYRA & - & 9.97 & +1.76 & $\mathrm{y}$ \\
\hline
\end{tabular}
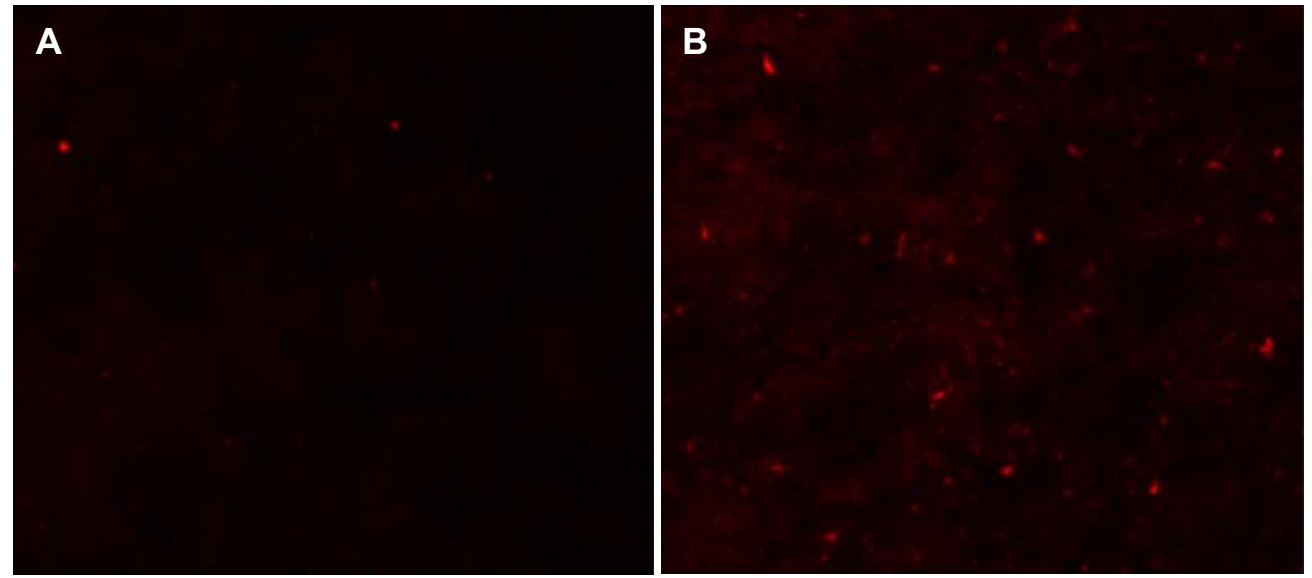

Fig. 1. Naive library (A) and selected (B) phage incubated on murine brain cryosections. A view on the posterior side of the cerebrum is shown. Phage were labeled with alexa-568. Magnification 20×. 


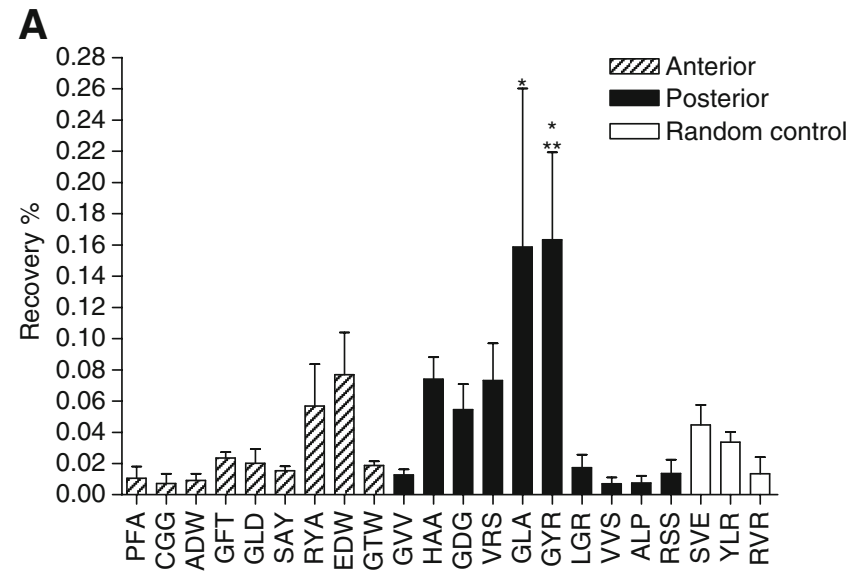

B

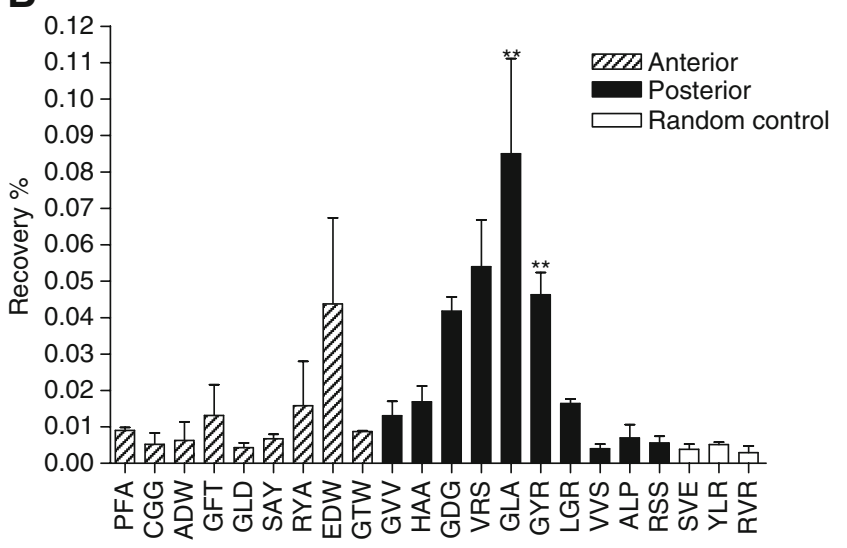

Fig. 2. Incubation of phage with hCMEC/D3 cells, recovery expressed as a percentage of the input. Mean \pm S.D.,$n=3$. A. Recovery of phage after glycine wash (cell surface-bound phage). One way ANOVA after log transformation to correct for non-Gaussian distributions with Newman-Keuls correction for multiple comparisons $* p<0.05$ GLA $v s$ RVR and GYR $v s$ YLR. ** $p<0.01$ GYR $v s$ RVR. B. Recovery of phage after subsequent cell lysis (strongly bound/ internalized phage). One way ANOVA after log transformation with Newman-Keuls correction for multiple comparisons $* * p<0.01$ vs all controls. Anterior $v s$ posterior Mann-Whitney test $p<0.01$.

phage GTW, and random control phage YLR. Phage GLA and GYR show significantly less affinity to HUVECs compared to hCMECs (Fig. 4), indicating that these phage do not have affinity to all endothelial cells and seem to be brain-endothelium specific.

To confirm their ability to bind to brain endothelium in situ, GLA, GYR, and random control phage RVR were individually perfused through the brain again in the in situ perfusion model. After perfusion and washing, phage were recovered from the brain, and the percentages of the input were determined (Fig. 5). Phage GYR showed a 5.0 times higher affinity to the brain than random control phage RVR. Phage GLA showed a 5.9 times higher affinity. This confirms that brain-binding phage were identified. Although the recovery percentages seem low, they are comparable to in vivo phage recovery percentages found by others (39).

After establishment of brain specificity in vitro, specificity was investigated in situ as well. The lung was considered a suitable control perfusion organ. Just like brain, lung comprises microvascular endothelium, and affinity of the phage for this endothelium was tested. Phage GLA, GYR, and control phage RVR were perfused through murine lungs and were processed in exactly the same way as was done for the brain perfusion. As is shown in Fig. 6, GLA binds significantly less to the lungs compared to control phage RVR. Binding of GYR is comparable to RVR. The negative charge of GLA is likely to be the cause of lower affinity to the lungs.

From both brain and lung recovery percentages, the preference ratio for brain over lung compared to RVR was calculated. Phage GYR showed a 8.5-fold preference, and phage GLA showed a 48-fold preference for brain over lung compared to the control, implying specific affinity of these phage-displayed peptides to brain endothelium.

To visualize the binding of phage GLA and GYR to human brain endothelial cells, hCMEC/D3 cells were incubated with single phage clones for $1 \mathrm{~h}$ at $37^{\circ} \mathrm{C}$. After washing, bound phage were stained with a labeled anti-phage antibody. Fluorescence microscopy showed phage staining throughout the cell monolayer. The pictures clearly show enhanced binding of selected phage GLA and GYR compared to the control phage RVR (Fig. 7). This is in agreement with the previous in vitro and in vivo experiments, and confirms the bloodbrain-barrier-targeting properties of these selected phagedisplayed peptides.

\section{DISCUSSION}

Using the powerful technique of phage display, we identified two peptides that show significant binding to the brain compared to a control peptide. It is interesting to see that two peptides with opposite net charges both bind to the blood-brain barrier. Cell membranes are negatively charged (44). Therefore, positively charged molecules may bind to the cell surface non-specifically by electrostatic interactions (45). Selected peptide GYR and control peptide RVR are both positively charged (Table I), yet GYR shows a significantly higher binding to the brain than RVR. Furthermore, the negatively charged GLA shows significant binding to the brain. These results indicate that the binding of the selected

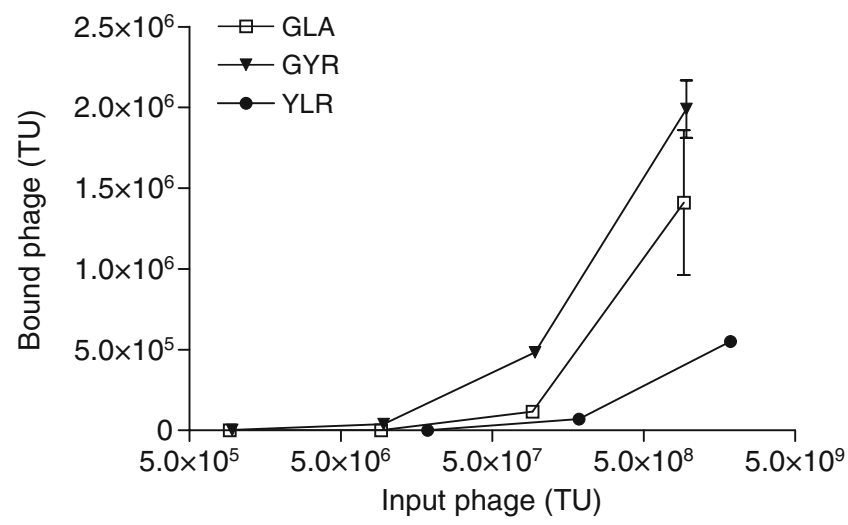

Fig. 3. Dose-response curve of phage GLA, GYR and control phage YLR. Mean \pm S.D., $n=2$. One way ANOVA after $\log$ transformation to correct for non-Gaussian distributions with Dunnet's correction for multiple comparisons against control. GLA and GYR vs YLR $p<0.01$. AUC is $14 \times$ and $26 \times$ higher for GLA and GYR, respectively. 
A

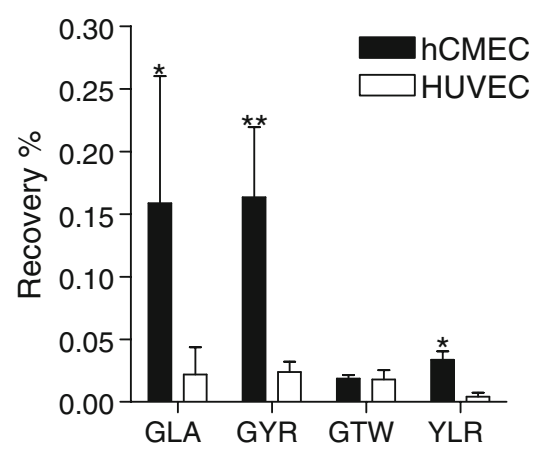

B

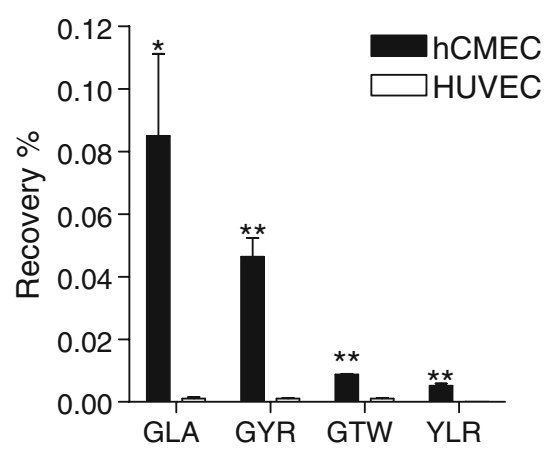

Fig. 4. Incubation of selected phage GLA, GYR, GTW and control phage YLR with hCMEC/D3 and HUVEC cells, recovery expressed as a percentage of the input. Mean $\pm \mathrm{S}$. D., $n=3$. A. Recovery of phage after glycine wash (cell surface-bound phage). B. Recovery of phage after subsequent cell lysis (strongly bound/internalized phage).Students t-test after $\log$ transformation to correct for non-Gaussian distributions. $* p<0.05, * * p<0.01$ hCMEC/D3 vs HUVEC.

peptides is dependent on more than electrostatic interactions with the endothelium.

When looking at the recovery from brain and lung, a notable difference in recovery percentages was evident. The base level of phage recovery from lung was higher than from brain. This can be explained by mainly two factors. First, traveling from heart to brain, the perfused fluid passes a longer distance compared to perfusion through the lung. Lungs are directly connected to the heart, allowing all of the perfused fluid to reach the lungs. For reaching the brain, fluids have to cover some distance, in which not all branching vessels (i.e. subclavian arteries) could be clamped. This may have resulted in increased loss of phage. Secondly, the total surface area of the lung vasculature is larger than the total brain surface area.

Identification of the peptide binding site can be an important step in the ligand discovery process. This can give insight into the ligand-target interaction and the uptake mechanism. The binding site should preferably be a receptor, which can specifically internalize a ligand, and the attached drug delivery vehicle, into the cells. Alternatively, nanocarriers such as liposomes can be delivered to transfer their

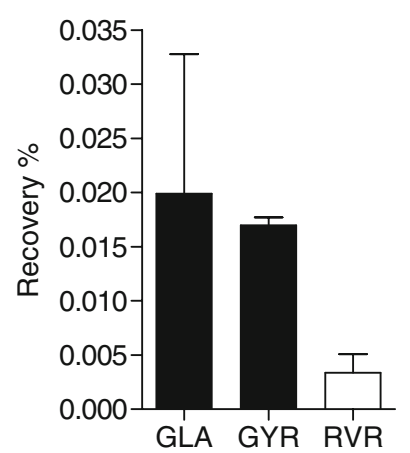

Fig. 5. Recovery of phage GLA, GYR, and control phage RVR from whole murine brains after phage perfusion and washing. Recovery is expressed as a percentage of the input. Mean \pm S.D., $n=3$. One way ANOVA after log transformation to correct for non-Gaussian distributions with Dunnet's correction for multiple comparisons against control. GLA and GYR vs RVR $p<0.01$. drug load to the target cells without the need for internalization. Lipophilic drugs can be transferred from liposomes to cell membranes when they are brought in close proximity by a targeting ligand (46). This can result in higher uptake of drugs with a low but not absent brain penetration capacity.

The GLA and GYR binding sites and potential uptake mechanisms are as yet unknown.

Because of the negative selection that was performed by perfusion through the heart, the binding site is likely to be brain-endothelium specific. Therefore, it could be a new, yet unidentified receptor, suitable for specific targeting to the blood-brain barrier.

A literature search showed that 4 out of the 34 selected peptides (PFA (47), GLD (48), SAY (49), and HAA (50)) had been selected before by other groups for very diverse purposes. Two possible explanations could account for this observation. These phage may have been selected in diverse settings because they contain biologically relevant motifs, suitable for multiple in vitro and in vivo applications. Alternatively, these motifs may also just enhance phage amplification rates, making them typical background phage that do not offer a specific target interaction.

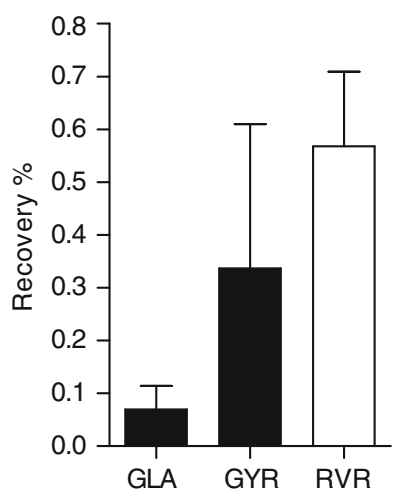

Fig. 6. Recovery of phage GLA, GYR, and control phage RVR from whole murine lungs after phage perfusion and washing. Recovery is expressed as a percentage of the input. Mean \pm S.D., $n=3$. One way ANOVA after log transformation to correct for non-Gaussian distributions with Dunnet's correction for multiple comparisons against control. GLA $v s$ RVR $p<0.05$. 

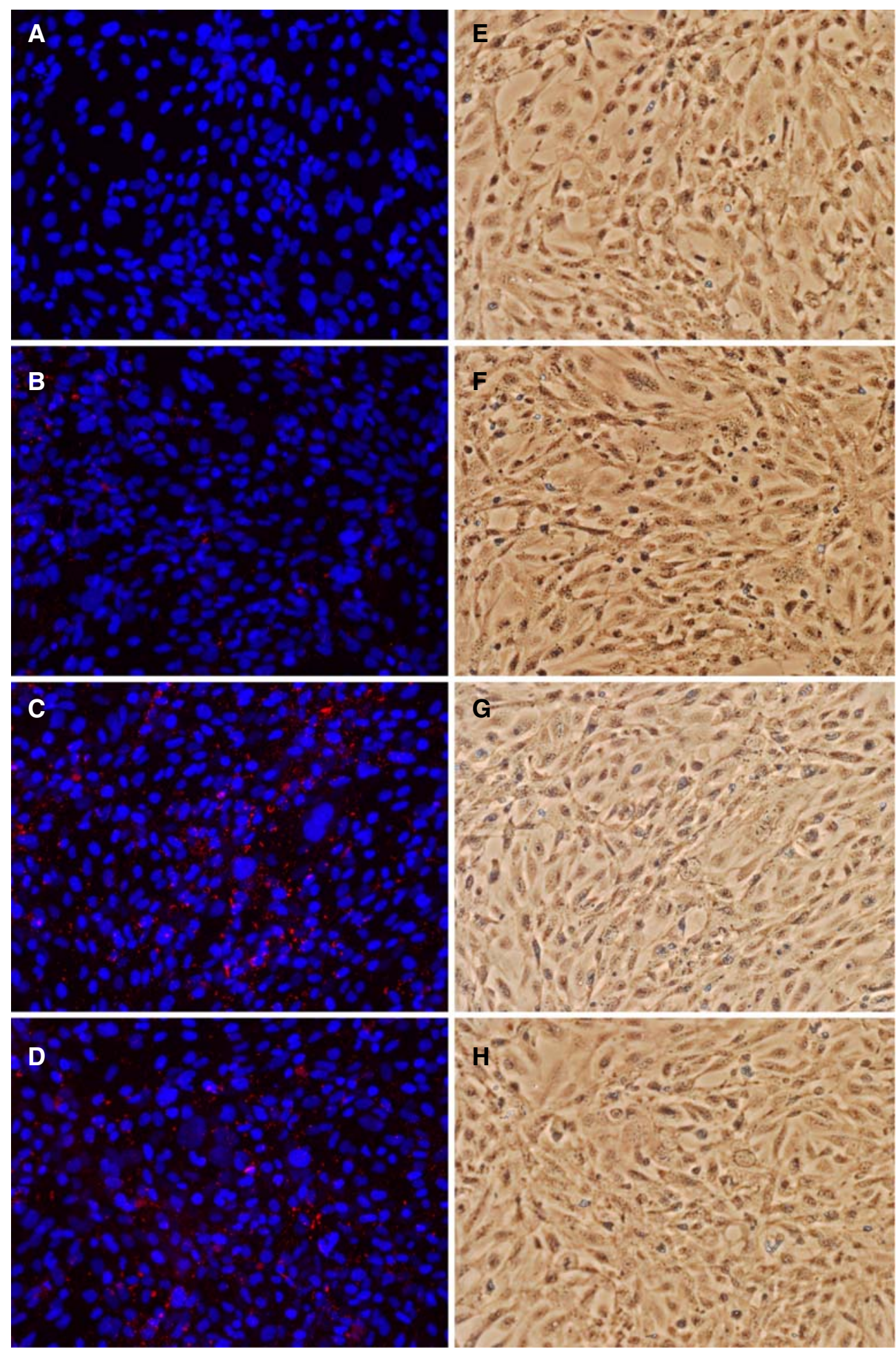

Fig. 7. Microscopic observation of hCMEC/D3 cells incubated with phage. A-D. Fluorescence microscopy image of phage labeled with alexa-568 (red) and DAPI-stained cell nuclei (blue). A. No phage. B. Control phage RVR. C. Selected phage GLA. D. Selected phage GYR. E-H. Light microscopy image of the same view on the cell monolayer as the fluorescence image to the left.

Our selected peptides, as they have been tested here, are expressed on a phage, displaying five peptides each. Attached to a nanoparticle (e.g. liposome), the number of peptides per particle can be greatly increased. This multivalency may result in a stronger binding of the targeted nanoparticle (i.e. avidity), compared to the phage tested here.

\section{CONCLUSION}

Two new peptides have been identified that may be used for specific targeting to the blood-brain barrier. In the future, these peptides could act as targeting ligands on nanoparticles to enhance uptake of CNS drugs into the brain. 


\section{ACKNOWLEDGEMENTS}

We thank George P. Smith for providing the phage display library and the host bacteria. This work was supported by Top Institute Pharma, project T5-105-1: nanoscience as a tool for improving bioavailability and blood-brain barrier penetration.

Open Access This article is distributed under the terms of the Creative Commons Attribution Noncommercial License which permits any noncommercial use, distribution, and reproduction in any medium, provided the original author(s) and source are credited.

\section{REFERENCES}

1. de Boer AG, Gaillard PJ. Drug targeting to the brain. Annu Rev Pharmacol Toxicol. 2007;47:323-55.

2. Calabria AR, Shusta EV. Blood-brain barrier genomics and proteomics: elucidating phenotype, identifying disease targets and enabling brain drug delivery. Drug Discov Today. 2006; 11:792-9.

3. Pardridge WM. Blood-brain barrier delivery. Drug Discov Today. 2007;12:54-61.

4. Garcia-Garcia E, Andrieux K, Gil S, Couvreur P. Colloidal carriers and blood-brain barrier (BBB) translocation: a way to deliver drugs to the brain? Int J Pharm. 2005;298:274-92.

5. Pardridge WM. Blood-brain barrier delivery of protein and nonviral gene therapeutics with molecular Trojan horses. J Control Release. 2007;122:345-8.

6. Jones A, Shusta E. Blood-brain barrier transport of therapeutics via receptor-mediation. Pharm Res. 2007;24:1759-71.

7. Lee HJ, Engelhardt B, Lesley J, Bickel U, Pardridge WM. Targeting rat anti-mouse transferrin receptor monoclonal antibodies through blood-brain barrier in mouse. J Pharmacol Exp Ther. 2000;292:1048-52.

8. Boado RJ, Zhang Y, Zhang Y, Pardridge WM. Humanization of anti-human insulin receptor antibody for drug targeting across the human blood-brain barrier. Biotechnol Bioeng. 2007; 96:381-91.

9. de Boer AG, van der Sandt IC, Gaillard PJ. The role of drug transporters at the blood-brain barrier. Annu Rev Pharmacol Toxicol. 2003;43:629-56.

10. Teixidó M, Giralt E. The role of peptides in blood-brain barrier nanotechnology. J Pept Sci. 2008;14:163-73.

11. Arap W, Haedicke W, Bernasconi M, Kain R, Rajotte D, Krajewski S, et al. Targeting the prostate for destruction through a vascular address. Proc Natl Acad Sci USA. 2002;99: 1527-31.

12. Zhang B, Zhang Y, Wang J, Zhang Y, Chen J, Pan Y, et al. Screening and identification of a targeting peptide to hepatocarcinoma from a phage display peptide library. Mol Med. 2007;13:246-54.

13. Lee T-Y, Lin C-T, Kuo S-Y, Chang D-K, Wu H-C. Peptidemediated targeting to tumor blood vessels of lung cancer for drug delivery. Cancer Res. 2007;67:10958-65.

14. Chen YH, Chang M, Davidson BL. Molecular signatures of disease brain endothelia provide new sites for CNS-directed enzyme therapy. Nat Med. 2009;15:1215-8.

15. Smith GP, Petrenko VA. Phage display. Chem Rev. 1997;97:391410.

16. Janzer RC, Raff MC. Astrocytes induce blood-brain barrier properties in endothelial cells. Nature 1987;325:253-7.

17. Gaillard PJ, van der Sandt ICJ, Voorwinden LH, Vu D, Nielsen $\mathrm{JL}$, de Boer AG, et al. Astrocytes increase the functional expression of P-glycoprotein in an in vitro model of the bloodbrain barrier. Pharm Res. 2000;17:1198-205.

18. Neuhaus W, Lauer R, Oelzant S, Fringeli UP, Ecker GF, Noe CR. A novel flow based hollow-fiber blood-brain barrier in vitro model with immortalised cell line PBMEC/C1-2. J Biotechnol. 2006;125:127-41.
19. Zacher AN, Stock CA, Golden JW, Smith GP. A new filamentous phage cloning vector: fd-tet. Gene 1980;9:127-40.

20. Nishi T, Budde RJA, McMurray JS, Obeyesekere NU, Safdar N, Levin VA, et al. Tight-binding inhibitory sequences against pp $60 \mathrm{c}$-src identified using a random 15-amino-acid peptide library. FEBS Lett. 1996;399:237-40.

21. Gao X, Kouklis P, Xu N, Minshall RD, Sandoval R, Vogel SM, et al. Reversibility of increased microvessel permeability in response to VE-cadherin disassembly. Am J Physiol Lung Cell Mol Physiol. 2000;279:L1218-25.

22. Shayo M, McLay RN, Kastin AJ, Banks WA. The putative blood-brain barrier transporter for the [beta]-amyloid binding protein apolipoprotein $\mathrm{j}$ is saturated at physiological concentrations. Life Sci. 1997;60:PL115.

23. McGuire MJ, Samli KN, Johnston SA, Brown KC. In vitro selection of a peptide with high selectivity for cardiomyocytes in vivo. J Mol Biol. 2004;342:171-82.

24. Liang S, Lin T, Ding J, Pan Y, Dang D, Guo C, et al. Screening and identification of vascular-endothelial-cell-specific binding peptide in gastric cancer. J Mol Med. 2006;84:764-73.

25. Lu D, Shen J, Vil MD, Zhang H, Jimenez X, Bohlen P, et al. Tailoring in vitro selection for a picomolar affinity human antibody directed against vascular endothelial growth factor receptor 2 for enhanced neutralizing activity. J Biol Chem. 2003;278:43496-507.

26. Kim Y, Lillo AM, Steiniger SCJ, Liu Y, Ballatore C, Anichini A, et al. Targeting heat shock proteins on cancer cells: selection, characterization, and cell-penetrating properties of a peptidic GRP78 ligand. Biochemistry 2006;45:9434-44.

27. Maruta F, Parker AL, Fisher KD, Murray PG, Kerr DJ, Seymour LW. Use of a phage display library to identify oligopeptides binding to the lumenal surface of polarized endothelium by $e x$ vivo perfusion of human umbilical veins. J Drug Target. 2003;11:53-9.

28. Laumonier C, Segers J, Laurent S, Michel A, Coppee F, Belayew A, et al. A new peptidic vector for molecular imaging of apoptosis, identified by phage display technology. J Biomol Screen. 2006;11:537-45.

29. Zou J, Dickerson MT, Owen NK, Landon LA, Deutscher SL. Biodistribution of filamentous phage peptide libraries in mice. Mol Biol Rep. 2004;31:121-9.

30. Dagenais C, Rousselle C, Pollack GM, Scherrmann J-M. Development of an in situ mouse brain perfusion model and its application to mdr1a P-glycoprotein-deficient mice. J Cereb Blood Flow Metab. 2000;20:381-6.

31. Rousselle C, Smirnova M, Clair P, Lefauconnier J-M, Chavanieu A, Calas B, et al. Enhanced delivery of doxorubicin into the brain via a peptide-vector-mediated strategy: saturation kinetics and specificity. J Pharmacol Exp Ther. 2001;296:124-31.

32. Bihorel S, Camenisch G, Gross G, Lemaire M, Scherrmann J-M. Influence of hydroxyurea on imatinib mesylate (Gleevec) transport at the mouse blood-brain barrier. Drug Metab Dispos. 2006;34:1945-9.

33. Willats WGT. Phage display: practicalities and prospects. Plant Mol Biol. 2002;50:837-54.

34. Hunsucker SW, Solomon B, Gawryluk J, Geiger JD, Vacano GN, Duncan MW, et al. Assessment of post-mortem-induced changes to the mouse brain proteome. J Neurochem. 2008;105:725-37.

35. Rajotte D, Arap W, Hagedorn M, Koivunen E, Pasqualini R, Ruoslahti E. Molecular heterogeneity of the vascular endothelium revealed by in vivo phage display. J Clin Invest. 1998;102:430-7.

36. Muruganandam A, Tanha J, Narang S, Stanimirovic D. Selection of phage-displayed llama single-domain antibodies that transmigrate across human blood-brain barrier endothelium. FASEB J. 2002;16:240-2.

37. Pasqualini R, Ruoslahti E. Organ targeting In vivo using phage display peptide libraries. Nature 1996;380:364-6.

38. Pasqualini R, Koivunen E, Ruoslahti E. alpha $v$ Integrins as receptors for tumor targeting by circulating ligands. Nat Biotech. 1997;15:542-6.

39. Arap W, Pasqualini R, Ruoslahti E. Cancer treatment by targeted drug delivery to tumor vasculature in a mouse model. Science 1998;279:377-80. 
40. Böckmann M, Drosten M, Pützer BM. Discovery of targeting peptides for selective therapy of medullary thyroid carcinoma. J Gene Med. 2005;7:179-88.

41. Weksler BB, Subileau EA, Perriere N, Charneau P, Holloway K, Leveque $\mathrm{M}$, et al. Blood-brain barrier-specific properties of a human adult brain endothelial cell line. FASEB J. 2005;19:1 8724.

42. Poller B, Gutmann H, Krähenbühl S, Weksler B, Romero I, Couraud $\mathrm{P}$, et al. The human brain endothelial cell line hCMEC/ D3 as a human blood-brain barrier model for drug transport studies. J Neurochem. 2008;107:1358-68.

43. Meyer SC, Gaj T, Ghosh I. Highly selective cyclic peptide ligands for NeutrAvidin and Avidin identified by phage display. Chem Biol Drug Des. 2006;68:3-10.

44. Zuhorn IS, Hoekstra D. On the mechanism of cationic amphiphile-mediated transfection. To fuse or not to fuse: Is that the question? J Membr Biol. 2002;189:167-79.

45. He J, Haney RM, Vora M, Verkhusha VV, Stahelin RV, Kutateladze TG. Molecular mechanism of membrane targeting by the GRP1 PH domain, boxs. J Lipid Res. 2008;49:1807-15.
46. Koning GA, Morselt HWM, Velinova MJ, Donga J, Gorter A, Allen TM, et al. Selective transfer of a lipophilic prodrug of 5fluorodeoxyuridine from immunoliposomes to colon cancer cells. Biochimica et Biophysica Acta (BBA)-. Biomembranes 1999;1420:153-67.

47. Li F, Dluzewski A, Coley AM, Thomas A, Tilley L, Anders RF, et al. Phage-displayed peptides bind to the malarial protein apical membrane antigen-1 and inhibit the merozoite invasion of host erythrocytes. J Biol Chem. 2002;277:50303-10.

48. Oku N, Asai T, Watanabe K, Kuromi K, Nagatsuka M, Kurohane $\mathrm{K}$, et al. Anti-neovascular therapy using novel peptides homing to angiogenic vessels. Oncogene 2002;21: 2662-9.

49. Pond CD, Marshall KM, Barrows LR. Identification of a small topoisomerase I-binding peptide that has synergistic antitumor activity with 9-aminocamptothecin. Mol Cancer Ther. 2006; 5:739-45.

50. Roos A, Nauta AJ, Broers D, Faber-Krol MC, Trouw LA, Drijfhout JW, et al. Specific inhibition of the classical complement pathway by C1q-binding peptides. J Immunol. 2001;167: 7052-9. 